\title{
A Research on the Status Quo and Reform of Swimming Teaching in Colleges and Universities in Beijing
}

\author{
Wen Yu \\ Basic Research Department of Beijing Electronic Science and Technology Institute, Beijing, 100070
}

\begin{abstract}
Swimming teaching is an important component of sports and health teaching. Teaching practice has proved that how to overcome adverse factors and to assist the students to master swimming skills within a limited time is a problem demanding prompt solution in the swimming teaching at colleges and universities. In this article, the author analyzes the status quo and existing problems in relation to the teaching objective, organizational form and method of swimming teaching in colleges and universities in Beijing and puts forward some suggestions on the reform of swimming teaching.

Index Terms - Colleges and universities, swimming teaching,
\end{abstract} reform

\section{I . Introduction}

College physical education is the connecting point between school physical education and social physical education as well as the key to life-long physical education. With high fitness and entertainment value, swimming is a sports activity in a special environment - water. However, only by learning to swim can one do body-building exercises in the form of swimming. At present, China has already issued Standards on Swimming Training in National Fitness Programs, calling on citizens to take an active part in swimming fitness activities. In this sense, colleges and universities should take full advantage of the school swimming pool complex to launch and deepen the reform of swimming teaching, so that each and every student can master the skill of swimming and benefit from this sport throughout their lives.

\section{II . Research object and methods}

\section{A. Research Object}

In this article, the research object is the swimming class in six colleges and universities in Beijing, including Peking University, China University of Petroleum, Beijing University of Post and Telecommunication, Beijing University of Technology, Beijing University of Aeronautics and Astronautics and Beijing Electronic Science and Technology Institute.

\section{B. Research Methods}

In this paper, the author relies on a series of research methods including literature study, questionnaire survey and interviews to analyze and discuss the status quo and reform of the swimming teaching in the six universities and colleges in Beijing.

\section{Results and analysis}

\section{A. Status Quo of Swimming Teaching in Colleges and Universities \\ 1) Basic Information about the Teaching Subject: Once} the students have mastered proficient breathing skills and can swim across a distance of over 15 meters in a certain swimming style, they can do independent body exercises by swimming. Therefore, this is set as the criterion for judging the student's mastery of swimming. According to statistics, nearly $70 \%$ of colleges students in Beijing cannot swim, with the proportion of girls higher than boys. Meanwhile, quite a number of students do not have any swimming basis at all.

2) Inadequate Teaching Management: According to our survey, all the six colleges and universities have their own indoor swimming pool. Moreover, two of them require their students to master swimming as a mandatory sports skill in the study period. These colleges and universities offer compulsory course and optional course for swimming, both assigning two hours for each weak. Since swimming itself is not an easy sport, both teachers and students complain that two teaching hours each week are not enough. This practical problem has resulted in long interval between two classes of swimming. Swimming teaching fails to form an integral system, making it harder for students to master the swimming skills. Furthermore, only two institutions control the class size within 16 students, compared with over 25 students in other universities. If one teacher is assigned to teach so many students, the overall teaching effect would be inevitably affected.

In the six colleges and universities surveyed, the swimming class is basically aimed to impart the basic skills and knowledge of one swimming style, the breaststroke. All the colleges and universities surveyed have different emphases on other swimming skills, including backstroke, freestyle, skills for starts and turns and first aid in water. One hundred percentage of the schools surveyed offer courses on basic skills and breaststroke. Four schools offer courses on freestyle, 4 on backstroke and 1 on butterfly stroke. Such contents as starts and turns, first aid in water and treading water are only introductory, with less time for practical training. As a result, it is hard to guarantee the learning effect.

3) Relatively Simple Teaching Method: Physical education teachers are inevitable human resources in offering swimming courses. In regular institutions of higher learning, the shortage of professional swimming teachers is a common problem. The problem of single teaching method also exists in swimming 
teaching. Most teachers still follow traditional teaching methods like imitation on the ground and exercise in the water, while some new and scientific teaching methods such as experience and heuristic teaching are severely lacking. In the teaching process, teachers' one-way teaching and students' oneway learning are also very common. Thus, on the part of students, passive acceptance of teachers' instruction has become a typical feature of swimming teaching.

4) Lack of After-class Practice and Coaching: Colleges and universities assign few class hours to swimming teaching. Because of limited teaching time, after-class practice has become a necessary supplement for class learning. After trying out the training method imparted by the teacher in class, students should do lots of after-class practice before mastering the skills to form a correct movement pattern. The survey has found that the after-class practice in regular institutions of higher learning mainly comes in the form of doing independent exercise, attending after-class remedial classes and taking part in the activities organized by swimming clubs. However, since independent practice is not guided by professional instruction, the training effect of most students is rather poor.

5) Unreasonable Evaluation System: Regular institutions of higher learning mostly take the distance and speed of swimming as the criterion for assessment. The introductory course mainly takes swimming distance as the testing content, but the standard established is quite low (15 meters). Although some students can reach the required standard, they cannot really swim.

\section{B. Several Thoughts on the Reform of Swimming Teaching at Colleges and Universities}

1) The teaching objectives and tasks of swimming teaching in regular institutions of higher learning should be clarified: Physical education in colleges and universities should emphasize on students' mastery of basic theoretical knowledge, basic techniques and basic skills. As a sport that has high fitness value and offers life-long benefits to students, swimming is the best choice. Therefore, colleges and universities should make the mastery of the swimming skills as a mandatory objective in swimming course.

2) The organization and management of teaching should be improved: In order to promote the popularization and improvement of swimming at colleges and universities, the first thing is to strengthen the organization and management of teaching, unify the guiding principle and make overall planning. School authorities should revise teaching programs and appropriately adjust teaching plans, offering compulsory teaching courses in freshman year, optional swimming course in sophomore year and follow-up course or public elective course in junior and senior year. They should select suitable teaching materials at different teaching stages and reasonably revise the test content, teaching methods and grading criterion for each stage.

It can be known from the law of forming swimming strokes and skills that the forming of stokes and skills is a developmental process in which a beginner learns to swim with increasing proficiency step by step. In this process, a continuous and effective stimulus can make students form conditioned reflex for skills, thus achieving the aim of consolidating and improving their skills. In swimming teaching, it is especially important to scientifically arrange the course interval and teaching hours. Experiments have proved that practicing every day is more effective than twice a week, while practice twice a day is more effective than once a week. Thus, the cycle of swimming teaching can be changed from long cycle (15 weeks) to short cycle (7-8 weeks), thus reducing the interval time between classes. Meanwhile, oncea-week swimming practice class should be increased to twicea-week, which may facilitate students' mastering of swimming techniques.

3) Hierarchical teaching should be fully implemented: Because of the difference in the aptitude and subjective efforts of the individuals, students show huge differences in the learning process. This requires teachers to proceed from the reality to reorganize the class according to students' practical capacity so as to carry out differentiated organization and hierarchical teaching in a more targeted manner.

The students can be divided into three groups. Group A is the students who have mastered some swimming skills; group $\mathrm{B}$ is the students who have ever entered the water, are not afraid of water but have nonstandard swimming skills; group $\mathrm{C}$ is the students without any swimming basis. In class teaching, the teacher needs to set the highest standards for Group A students, requiring them to practice independently, which is supplemented by group training. The teacher should focus on guiding students' self study and self practice, with girls and boys to learn in the same class. As for the students in group B and group $\mathrm{C}$, the teacher needs to follow the principle of progressive education, guiding them to master the most basic contents in the teaching program. The main practice form should be group training. Meanwhile, the teacher needs to offer individual coaching based on the individual differences, teaching girls and boys in different classes. This grouping method is conducive to teachers' organization of teaching and individual coaching. Meanwhile, this can also facilitate the information exchange between students as well as between students and teachers so as to fully mobilize the learning initiative and enthusiasm of different levels of students. At the same time, the teacher should make it clear to the students that the initial grouping is not changeless. There is no time limit for upgrading or downgrading. The students are allowed to make any adjustment with the consent of the teacher if their swimming skills have progressed or failed to keep pace with the rest of the class. In short, the design and implementation of class teaching should be based on the individual differences of students, so that different levels of students can be guided to learn in their own "zones of proximal development".

4) Appropriate teaching methods should be chosen at the right moment: The priority in hierarchical teaching is to choose appropriate teaching methods. Swimming teachers should constantly improve their professional skills, carefully study the teaching syllabus and materials, set highly operable and feasible phased teaching objectives, teaching tasks and 
specific teaching requirements to make the teaching content more targeted.

As a sporting event carried out in water environment, swimming has some distinct characteristics and difficult points not seen in other events. Thus, teachers should select effective methods for swimming teaching and make bold innovation. There is a wide choice among swimming teaching methods available, such as heuristic teaching, situational teaching, programmed teaching, model teaching, multimedia computer assisted teaching, deepwater teaching, parallel coherent teaching and hierarchical teaching. The teaching should simplify some cumbersome links and highlight accelerated swimming course.

For example, in class A, parallel coherent teaching can be adopted. Based on motor skill migration, this method adopts two different styles or synthesizes the styles with basically the same movement structures and teaches students this style or movement at the same time or one by one, for example, water treading, breaststroke, backstroke, crawl stroke, butterfly breast stroke and butterfly stroke. This method ca not only enrich the teaching content and speed up the teaching, but also raise students' learning interest. Deepwater teaching method can be tried out in class $B$ to cure the beginners of the dependence on the ground, and to break the self-protective psychology and reinforce learning. In this way, students can learn to move freely in deepwater environment and take the initiative to learn how to float and swim forward in the water. In class $\mathrm{C}$, teachers can adopt model teaching or hierarchical teaching by following the psychological laws in cognitive learning to divide the teaching stage, so that the teaching would be more logical, hierarchical and progressive.

Meanwhile, "teacher teaching students" can be closely combined with "students teaching students" to give full play to the learning initiative of each and every student. At the early teaching stage, the teacher can help each student overcome the fear of water by "group working". In the middle stage, the teacher can help students timely detect an error and effectively correct by "one-to-one mirroring". In the final stage, the teacher can help most students consolidate their skills and strokes by "independent learning". In different stages, the teacher can also rely on advanced multimedia teaching means to help the students learn about the key techniques of swimming through the collection and display of video, thus effectively improving the swimming teaching quality. As exercise density is key to a good swimming class, a correct control of exercise density is a magic weapon for a successful swimming teacher. The exercise density for a swimming class should be controlled between $70 \%$ and $80 \%$, for blind exercise is as ineffective as excessive talk.

5) The learning in and after class should be combined to build a new mode for swimming teaching: Motor skill teaching should generally undergo three stages: the stage of roughly grasping the movement, the stage of improving and perfecting the movement and the stage of consolidating and freely applying the movement. Since the time for class exercise is rather limited, most students can only make it to the stage of roughly grasping the skills and movements or the stage of improving and perfecting the movements. In order to overcome the restriction of inadequate teaching hours on the accomplishment of teaching objectives, swimming teaching can be carried out by combining class teaching with after-class practice. Constant practice and consolidation are the key to mastering swimming strokes and skills. Therefore, diversified forms of supportive activities should be carried out after class, such as setting up a swimming club, offering tutorial class for the students who have failed the swimming test and organizing after-class swimming contests. In order to achieve the desired effect in after-class exercise, a proper number of swimming teachers should be equipped in the organization and coaching of after-class practice so as to facilitate the swimming training for students with the learning needs.

6) The evaluation methods for swimming teaching should be rationally designed: Test is a major means to check the teaching effect and get the feedback information. A correct and objective evaluation of students' progress can motivate students to work even harder. Regular institutions of higher learning should introduce Standards on Swimming Training in National Fitness Programs to swimming teaching, combining the two closely together. In this way, both students' enthusiasm in practice and teachers' teaching initiative can be fully mobilized by means of teaching assessment and organizing contests, thus improving the teaching effect. The formulation of evaluation criterion should be dynamic and differentiated. The school should use diagnostic evaluation, increase the proportion of process assessment and reduce summative assessment to ensure timely evaluation, timely feedback and timely correction. A rational use of these evaluation methods can help students keep up with the status, advantages and disadvantages of their mastery of skills and mobilize their learning motivation. In this way, all students can receive the most effective training in the shortest possible time, experiencing the excitement in swimming and tasting the joy of success.

\section{IV . Conclusion}

A. Swimming is hailed as one of people's favorite sporting events in the 21 st century. From the perspectives of practical value and lifelong benefits, it is advisable to popularize swimming sport at colleges and universities and establish the teaching objective that all colleges students should master the skill of swimming. In order to implement the objective, colleges and universities should scientifically revise the teaching syllabus, enrich the teaching content, change the teaching cycle, ensure the class hours and improve the evaluation criterion.

B. Swimming teaching should be implemented on the basis of students' practical situations, and hierarchical and differentiated teaching should be comprehensively carried out to fully mobilize the learning initiative and enthusiasm of different levels of students, which is conducive to teachers' organization of teaching and facilitate students' learning. 
$C$. The teacher should choose proper teaching modes and methods at different stages of teaching for different levels and the same level of students, reasonably arrange exercise density and effectively promote students' learning and improvement of swimming skills.

$D$. Considering the particularity of swimming sport and inadequate class hours for swimming teaching in regular institutions of higher learning, after-class practice is an important supplement to class teaching. Thus to combine class teaching with after-class practice is an effective mode.

$E$. The formulation of swimming evaluation criterion should be dynamic and differentiated. In the teaching process, the teacher should properly use diagnostic evaluation, increase the proportion of process evaluation and reduce summative evaluation, so that all students can receive the most effective training within the shortest possible time, experiencing the excitement in swimming while tasting the joy of success.

\section{References}

[1] Mei, X. X. Swimming sport. Higher Education Press. April, 2001, (2).

[2] Ma, L. P. Current situation and reform research on the swimming teaching in regular institutions of higher learning. Fujian Sports Science and Technology. 2003 (10), 48-50.

[3] J. Ma, "The impact of course hours, exercise density and coherence of swimming classes on teaching quality," Journal of Guangzhou Sports University. 2003 (2), 60-63.

[4] X. Ye, "Design and use of evaluation methods in swimming teaching." Journal of Beijing Sport University, 2003(1), 80-81.
[5] Y. Song, "Reform and practice in the swimming teaching mode in regular institutions of higher learning," Journal of Beijing Sport University, 2000, (9), 393-394.

[6] M. Zhang, "Reform research on the public swimming course in Jimei University," Sport Science Studies, 2005 (3), 74-78.

[7] $\mathrm{H}$. Li, "A survey research on the status quo of swimming teaching at colleges and universities of Fujian Province," Journal of Capital Institute of Physical Education, 2005 (5), 81-83.

[8] A. Zhang, "An experimental study on the implementation of researchoriented teaching in swimming teaching," Journal of Physical Education, 2005 (4), 131-133.

[9] H. Cai, "A pilot study on the application of the strategy of "cooperative teaching and three-dimensional evaluation",". China Sport Science and Technology, 2002 (12), 20-21.

[10] W. Chen, "A research on the teaching mode of "combining class teaching with after-class practice" in swimming teaching at regular institutions of higher learning," Journal of Nanjing Physical Education Institute (Natural Sciences). 2003 (6), 79-81.

[11] L. Chen, "The status quo and reform plan for the general swimming course at colleges and universities," Swimming, 2002 (3), 26-27.

[12] D. He, "Application of synchronous teaching method in swimming teaching," Liaoning Sport Science and Technology, 2003 (4), 53.

[13] C. Le, "An experimental study on the process evaluation of backstroke teaching in general swimming courses at sports colleges and universities," Wuhuan Institute of Physical Education. 2008.

[14] L. Zhang, "A study on the characteristics and appropriate training methods at different stages of motor skill learning in physical education," Journal of Nanjing Physical Education Institute, 2001 (6), 93-94.

[15] Y. Liu and S. Li, "Status quo and countermeasure research on the swimming courses in regular institutions of higher learning in Beijing," Sport, 2009 (11), 107-108. 